\title{
The Transportation Infrastructure and Regional Economic Growth-Evidence from Dongguan Humen Bridge
}

\author{
Qiuming Lai \\ School of Economics, Jinan University, Guangzhou, China \\ Email: 15917902178@163.com
}

How to cite this paper: Lai, Q. M. (2020). The Transportation Infrastructure and Regional Economic Growth-Evidence from Dongguan Humen Bridge. Modern Economy, 11, 2055-2080.

https://doi.org/10.4236/me.2020.1112137

Received: November 5, 2020

Accepted: December 26, 2020

Published: December 29, 2020

Copyright $\odot 2020$ by author(s) and Scientific Research Publishing Inc. This work is licensed under the Creative Commons Attribution International License (CC BY 4.0).

http://creativecommons.org/licenses/by/4.0/

\section{(c) (i) Open Access}

\begin{abstract}
Transportation infrastructure is an important factor driving regional economic growth, and scientifically evaluating the economic growth effects of key transportation infrastructure is an important theoretical issue of development economics. This paper takes the opening of Dongguan Humen Bridge as a quasi-natural experiment, and quantitatively identifies the regional growth effect it brings. This paper uses panel data from 21 prefecture-level cities in Guangdong Province from 1991 to 2007, and based on the synthetic control method, assigns different weights to the cities in the control group to construct the "counterfactual" state of Dongguan where the Humen Bridge is not opened, so as to compare the difference in economic development between "real Dongguan City" and "Synthetic Dongguan City". The results show that the opening of the Humen Bridge in 1997 made Dongguan's GDP and GDP per capita exceed the theoretical level that could be achieved when the Humen Bridge was not opened. The opening of the Humen Bridge significantly changed the economic growth trend of Dongguan. With the passage of time, the opening of the Humen Bridge has continuously strengthened the promotion of Dongguan's economic growth, indicating that the transportation infrastructure has a long-term effect on the promotion of regional economic growth. This work advances the research on the relationship between transportation infrastructure and regional economic growth.
\end{abstract}

\section{Keywords}

Synthetic Control Method, Humen Bridge, Economic Growth

\section{Introduction}

The role of transportation infrastructure in economic growth and regional coor- 
dinated development has always been the key content of Chinese and Western scholars. At the same time, investment in transportation infrastructure with typical externalities of public goods has always been an important means for the government to carry out macroeconomic regulation and control, and it is also regarded as one of the important measures to promote economic growth and sustainable development. The huge investment in infrastructure such as railways, highways and aviation in the early Western capitalist countries promoted rapid economic development and accelerated the process of industrialization and urbanization in Western countries (Aschauer, 1989; Button \& Taylor, 2000; Atack et al., 2010). With the gradual formation of economic globalization and world market integration, the rapid development of some developing countries has also proved the importance of transportation infrastructure to regional economic development (Demurger, 2001; Banerjee et al., 2012; Pradhan \& Bagchi, 2013; Liu \& Hu, 2010; Zhang, 2012).

China began to implement reform and opening-up in 1978, and then promoted market-oriented reforms, which brought about increasing demand for infrastructure investment and construction. In the mid-1990s, especially since the "Asian Economic Crisis", in order to cope with the problems of insufficient demand and the decline in economic growth, the Chinese government had implemented a proactive fiscal policy to strengthen infrastructure construction to drive economic development (Institute of Industrial Economics of CASS, 2002). After the millennium, China joined the World Trade Organization, the domestic market had been further opening up, and inter-regional demand for production factors such as labor, capital, and technological exchanges increased. Affected by the global financial crisis in 2008, the Chinese government once again introduced a "four trillion investment" investment package, of which nearly $40 \%$ of the investment will be used for major infrastructure projects, such as railways, highways, airports, water projects and urban power grid transformation. It can be seen from this that whether it is during the economic boom or the economic downturn, the characteristics of infrastructure investment and construction that can be used as intermediate products and final products are self-evident for economic development.

Reviewing the previous literature, most studies have included transportation infrastructure in public infrastructure, or extracted transportation facilities from infrastructure as a separate capital variable of the measurement model to estimate its output elasticity (Aschauer, 1989; Garcia-Mila \& McGuire, 1992), or studied its relationship with economic growth, changes in regional industrial structure, micro-individual behavior, and the spillover effects of transportation infrastructure itself (Krugman, 1991; Fernald, 1999). There are few researches that directly assess the impact of the opening of a key transportation infrastructure in an important geographic location on economic development. However, for areas in key geographical locations, the construction of important transportation hubs can often affect the local economic development level, such as Suez 
Canal in Egypt, the Channel Tunnel between Britain and France, the Golden Gate Bridge, the Panama Canal and so on. The opening of the transportation infrastructure in these important geographical locations not only directly improves the efficiency of the exchange of people and the flow of goods, but also creates huge revenue for the local area every year. The economic benefits are considerable.

Therefore, on the basis of learning from previous literature studies, this paper will be based on a brand-new perspective, with transportation hubs in important locations as the entry point, using the Synthetic Control Method (SCM) in policy evaluation to study key transportation foundations The impact of the opening of facilities on the development of the regional economy in turn gives a relatively stable result. This article believes that the Dongguan Humen Bridge is undoubtedly a key transportation infrastructure in China's regional economy, and it provides us with an excellent quasi-natural experimental scenario for analyzing the impact of the opening of transportation infrastructure on regional economic growth. This paper uses panel data from 21 prefecture-level cities in Guangdong Province from 1991 to 2007. The rest of the paper is organized as follows: the second part is literature review and analysis; the third part is estimation methods and data description; the fourth part is empirical results and analysis; the fifth part is the robustness test; the sixth part is the conclusion and policy recommendations.

\section{Literature review and analysis}

The upsurge of empirical research on transportation infrastructure by foreign economists began in the late 1980s. The pioneering research came from Aschauer (1989), who included transportation infrastructure into public infrastructure and considered the economic growth benefits of the overall infrastructure. He proved that the "core" infrastructure promotes economic growth, with significant output elasticity estimates of 0.24. Barro (1990) based on modern endogenous growth theory, pointed out that public infrastructure can overrate the long-term economic growth rate. However, some scholars pointed out that the estimation results using the time series method may overestimate the output elasticity of infrastructure (Tatom, 1991). Krugman (1991) used the research methods of regional economics and geographic economics and found that the emergence of the "core-periphery pattern" depends on transportation costs, and the reduction of transportation costs will make the industry appear at the same time. When the balance between the centripetal force and the centrifugal force is broken, the industry will have a "core-periphery" structural distribution. Venables (1996) studied the position changes of vertically connected industries in the face of changes in transportation costs. He found that when transportation costs are reduced from high to low, the first thing that appears is the concentration of economic structure and income, and the gap in regional economic structure and per capita income has widened. But further reductions may disrupt agglomeration and bring convergence. Fedderke and Bogetic (2009) examined the 
impact of infrastructure on South Africa's manufacturing industry and found that infrastructure has a direct impact on labor productivity and infrastructure has an indirect impact on total factor productivity. Roberts et al. (2012) adopted a counterfactual method based on the hybrid estimation correction of the "New Structural Economic Geography" model to evaluate China's expressway network expansion plan. They believed that the expressway network seems to reinforce the existing pattern of spatial inequality. But over time, these spatial development inequalities will decrease due to increased migration. In addition, convenient transportation infrastructure is also one of the important basic conditions for promoting regional trade development (Bougheas et al., 1999; Limao \& Venables, 2001; Francois \& Manchin, 2013). Furthermore, some scholars have studied the connection between the individual transportation infrastructure and international trade, and concluded that the development of transportation infrastructure and the improvement of transportation efficiency have a positive and positive effect on trade (Nordas \& Piermartini, 2004; Clark et al., 2004; Fujimura \& Edmonds, 2006).

But not all studies tend to hold that there is a direct or indirect link between transportation infrastructure and economic growth. For example, Holtz-Eakin and Schwartz (1995) believe that the relationship between transportation infrastructure and economic growth is not obvious. Later, after exploring the impact of infrastructure on economic growth, some scholars came to conclusions similar to those of Holtz-Eakin and Schwartz (Evans \& Karras, 1994a, 1994b; Chandra \& Thompson, 2000).

In China's research, some documents focus on the impact of China's transportation infrastructure on economic growth. Huang and Li (2006) put forward the viewpoint of expanding the market scale by further improving the transportation infrastructure of provinces and cities in the Mainland, so as to give play to the role of market scale in determining economic growth performance. Wang and Wang (2007) concluded that infrastructure plays a dominant role in economic growth. Zhang $(2007,2012)$ separated transportation infrastructure as a separate form from capital. His research found that China's transportation infrastructure investment and economic growth showed strong spatial agglomeration characteristics, and the spatial spillover effect on inter-regional economic growth is very significant. Liu and Hu's (2010) study found that transportation infrastructure has a significant positive role in promoting China's economic growth. Liu (2010) studied the spatial spillover effect of the stock of fixed capital of road and water transportation on China's economic growth and found that the stock of fixed capital of road and water transportation on the whole has a positive effect on regional economic growth. Liu and $\mathrm{Hu}$ (2011) pointed out that the improvement of transportation infrastructure has had a significant positive impact on China's regional trade, and the improvement of transportation infrastructure has promoted regional economic integration. Zhou and Zheng (2012) used the DID method to investigate the impact of railway acceleration on eco- 
nomic growth and found that compared with the stations without acceleration, the stations with acceleration of railway increased the per capita GDP growth rate by about $3.7 \%$, and the promotion effect of acceleration of railway on economic growth was more obvious in the later period.

Furthermore, some scholars had begun to study the relationship between transportation infrastructure and total factor productivity (TFP). They found that transportation infrastructure has a positive impact on total factor productivity (Liu et al., 2010; Zhang \& Yi, 2012). In addition, some scholars believe that investment in transportation infrastructure construction also plays an important role in promoting regional industrial clusters (Ren \& Zhang, 2010). Sheng et al. (2011) found that infrastructures have a positive effect on the export of Chinese enterprises. Ruan (2017) studied the investment and economic effects of transportation infrastructure planning in the Silk Road Economic Belt and found that the impact of railways and highways on import and export trade was significantly positive.

There are also researchers who explore the impact of transportation infrastructure on the micro-level of corporate behavior or residents' behavior from a micro perspective. Li and Li (2009) believed that the construction of high-grade roads significantly reduced the inventory capital occupation of Chinese manufacturing enterprises, while the investment of ordinary roads and railways had no significant impact on the inventory level of enterprises. Shi et al. (2018) found that the railway acceleration had played a positive role in technological progress and efficiency improvement of enterprises and promoted the growth of total factor productivity. From the perspective of corporate inventory, Zhang et al. (2018) explored the mechanism behind transportation infrastructure to promote economic growth under a unified framework and verified that transportation infrastructure plays an important role in expanding enterprise scale, improving enterprise operating efficiency and enhancing market vitality. Guo et al. (2019) found that road infrastructure not only has a "multiplier effect" that can directly promote economic development, but also can indirectly promote economic growth through the residents' "consumption effect".

A review of the previous research literature shows that the research on the relationship between transportation infrastructure and economic development has made great progress. Domestic and foreign literature is mostly empirical research, and most of them focus on the aspects of transportation infrastructure promoting changes in the production field. It is believed that the investment and construction of transportation infrastructure mainly affects economic development by affecting the flow of factors in the production field.

In research methods, the cost function method and production function method are mainly used to measure the impact of transportation infrastructure on economic development. In terms of the data, time series data is mainly used for analysis in the early stage, and the output elasticity obtained based on this method is relatively high; In recent years, mainly based on panel data analysis, the 
output elasticity will be low, and it cannot be ruled out that the impact of transportation infrastructure on economic growth is not significant. However, the overall research results still tend to have a positive impact on economic growth. In terms of research content, the research literature has gradually expanded from exploring the relationship between transportation infrastructure and economic growth to specific areas, such as the impact of transportation infrastructure on regional industrial structure, import and export trade, location selection of industry enterprises, and individual behavior decisions. The selection of research indicators is still relatively single. Early research mainly focused on the stock of transportation infrastructure, and later gradually evolved to extract specific levels of transportation infrastructure from the overall for individual research; with the research boom of new economic geography With the rise, spatial and geographic factors are gradually being considered, and then the spillover effect of transportation infrastructure is discussed. However, it is rare to study the impact of a specific infrastructure on regional economic growth, which also limits our understanding of regional economic development by building transportation infrastructure in special locations between regions.

In fact, the economic development of many regions and the changes in the geo-spatial pattern of regional and even national economic development are largely dependent on the impact of the completion and opening of key infrastructure. Based on this important background with both theoretical value and practical significance, this paper selects the opening of the Dongguan Humen Bridge as a quasi-natural experiment, and uses the cutting-edge analysis methods of policy evaluation to explore its impact on economic growth, which undoubtedly forms an important supplement to the existing literature and existing research boundaries.

\section{Estimation Method and Data Description}

\subsection{Background}

The transportation infrastructure of Dongguan is the hardware foundation that supports and leads the development of Dongguan and surrounding areas. In order to strengthen exchanges and ties with the west bank of the Pearl River, Humen Automobile Ferry Port was completed and put into operation in 1991, but shortly there was a problem of insufficient capacity. As a result, Guangdong Provincial Government began to promote the Humen Bridge construction project. On June 9, 1997, the Humen Bridge was officially opened for operation. In this context, for this article we regards the opening of the Humen Bridge as a policy implemented by the Guangdong Provincial Government and uses the method of policy evaluation to evaluate the impact of the opening of the Humen Bridge on the regional economic development. The methods for evaluating policy items mainly include difference-in-differences (DID), propensity score matching method (PSM) and composite control method (SCM). However, it is worth noting that, according to the construction history of Humen Bridge, the 
opening of this important transportation infrastructure is not a random occurrence. At the same time, the opening of Humen Bridge may have systemic differences relative to other regions. Considering the limitations of the DID method and the PSM method, this paper will choose the data-driven method SCM as the main analytical method. The next thing to do is to introduce the synthetic control method in detail, and then defines and explains the main variables and sample data.

\subsection{Model Framework}

The Synthetic Control Method (SCM) was first proposed by Abadie and Gardeazabal (2003). They used it to study the economic impact of terrorist activities in the Basque Country in Spain. Since then, this method has been widely used in the field of policy evaluation (Abadie et al., 2010; Ando, 2015; Wang \& Nie, 2010; Liu \& Fan, 2013; Liu \& Wu, 2017; Liu \& Zeng, 2018). The characteristic of the synthetic control method is that it is driven by data and selects suitable individuals from the control group to synthesize the "counterfactual" processing group. The basic idea of this method is to select a reasonable control group and predictor variables, synthesize a "counterfactual" treatment group based on the control group and the existing predictor variables, and then the difference between the "synthetic treatment group" and the "real treatment group" was compared to assess the impact of the policy. One of the prerequisites is that the sum of the weights of the control group areas participating in the synthesis "processing group" is 1 , in order to avoid excessive extrapolation in the synthesis control. The following will briefly introduce the basic principles and models of the SCM.

Assuming that the observable region is $J+1$, the time span of the sample is [ 1 , T]. During the period of $T 0$ (June 1997), individual 1 had an important traffic infrastructure opening (corresponding to the opening of Humen Bridge in the paper), in which $1 \leq T_{0}<T$; Other $J$ regions serve as potential control groups for region 1; After time $T_{0}$, area 1 was constantly affected by the opening of the bridge. We use $Y_{i t}^{N}$ to represent the economic development of region $I$ that was not affected by the opening of Humen Bridge at time $T$, and $Y_{i t}^{I}$ represent the economic development of region $I$ that was affected by the opening of Humen Bridge at time $T$, in which $i \in[1, J+1], t \in[1, T] . \alpha_{i t}$ represents region $I$ with the effect of Humen Bridge opening, and the following model is set:

$$
Y_{i t}=Y_{i t}^{N}+D_{i t} \alpha_{i t}
$$

$D_{i t}$ represents the virtual variable of whether there is an important traffic infrastructure opened in area $I$,

$$
D_{i t}= \begin{cases}1, & i=1 \text { and } t>T_{0} \\ 0, & i \neq 1 \text { or } t \leq T_{0}\end{cases}
$$

When $t \leq T_{0}$, for all regions $i$ is $Y_{i t}=Y_{i t}^{N}=Y_{i t}^{I}$; when $t>T_{0}$, the economic effect of the humen bridge opening on region 1 at time $t$ is $\alpha_{1 t}=Y_{1 t}^{I}-Y_{1 t}^{N}$. There- 
fore, $\alpha_{1 t}$ is the treatment effect to be estimated in this paper. However, $Y_{1 t}^{I}$ region $i$ can be observed after the bridge is opened. But the potential results of $Y_{1 t}^{N}$ unaffected by the bridge opening after $T_{0}$ cannot be observed. Therefore, referring to the practice of Abadie et al. (2010), the following factor model was used to estimate the "counterfactual result $Y_{1 t}^{N}$ " that region I was not affected by the bridge opening after $T_{0}$.

$$
Y_{i t}^{N}=\delta_{t}+\theta_{t} Z_{i}+\lambda_{t} \mu_{i}+\varepsilon_{i t}
$$

$\delta_{t}$ is a fixed time effect with the same influence on all sample units; $Z_{i}$ is a $(r \times 1)$-dimensional vector that contains observable variables that are not affected by the opening of the bridge in area $i$, and $\theta_{t}$ is an unknown parameter of $(1 \times r)$ dimensions Vector; $\mu_{i}$ is a $(F \times 1)$-dimensional coefficient vector, $\lambda_{t}$ is a $(1 \times F)$-dimensional unobservable common factor vector; $\varepsilon_{i t}$ is an error term, representing a temporary shock that cannot be observed in each sample area, and the mean is zero.

When $t>T_{0}$, in order to estimate $Y_{i t}^{N}$, we consider to construct the weight vector $\left.W=\left(w_{2}, \cdots, w_{J+1}\right)\right)^{\prime}$, the weight vector satisfies $w_{j}>0, j=2, \cdots, J+1$. For all $w_{j}$, satisfy the $\sum_{2}^{J+1} w_{j}=1$. Here, the weight is set to non-negative and the limit is 1 , the purpose is to avoid excessive extrapolation, so that the control group can synthesize a feasible synthetic experimental group within the observable data range. Each specific value of vector $W$ represents the composite control for the first region, which is a weighted average of all regions within the control group. By weighting the variable values of each control group region, we can get:

$$
\sum_{j=2}^{J+1} w_{j} Y_{j t}=\delta_{t}+\theta_{t} \sum_{j=2}^{J+1} w_{j} Z_{j}+\lambda_{t} \sum_{j=2}^{J+1} w_{j} \mu_{j}+\sum_{j=2}^{J+1} w_{j} \varepsilon_{i t}
$$

Suppose there is a vector group $W^{*}=\left(w_{2}^{*}, \cdots, w_{J+1}^{*}\right)$, for the target city $j=1$ that has traffic infrastructure open at $t \in\left[1, T_{0}\right]$ satisfy:

$$
\sum_{j=2}^{J+1} w_{j}^{*} Y_{j, 1}=Y_{1,1}, \sum_{j=2}^{J+1} w_{j}^{*} Y_{j, 2}=Y_{1,2}, \cdots, \sum_{j=2}^{J+1} w_{j}^{*} Y_{j, T_{0}}=Y_{1, T_{0}}, \sum_{j=2}^{J+1} w_{j}^{*} Z_{j}=Z_{1}
$$

Abadie et al. (2010) proved that if $\sum_{t=1}^{T_{0}} \lambda_{t}^{\prime} \lambda_{t}$ is a nonsingular matrix, then we can get:

$$
\begin{aligned}
Y_{1 t}^{N}-\sum_{j=2}^{J+1} w_{j}^{*} Y_{j t}= & \sum_{2 j=2}^{J+1} w_{j}^{*} \sum_{s=1}^{T_{0}} \lambda_{t}\left(\sum_{n=0}^{T_{0}} \lambda_{n}^{\prime} \lambda_{n}\right)^{-1} \lambda_{s}^{\prime}\left(\varepsilon_{j s}-\varepsilon_{1 s}\right) \\
& -\sum_{j=2}^{J+1} w_{j}^{*}\left(\varepsilon_{j t}-\varepsilon_{1 t}\right)
\end{aligned}
$$

It can be proved that formula (4) tends to 0 under general conditions. Therefore, when $t \in\left(T_{0}, T\right), \quad \sum_{j=2}^{J+1} w_{j}^{*} Y_{j t}$ can be used as the counterfactual result of the processing group (area 1 ), thus the estimated value of policy $\widehat{\alpha_{i t}}$ can be obtained:

$$
\widehat{\alpha_{i t}}=Y_{1 t}-\sum_{j=2}^{J+1} w_{j}^{*} Y_{j t}, T_{0}<t \leq T
$$

The key to solving $\widehat{\alpha_{i t}}$ is to find the weight vector $W^{*}$ that makes the above equation hold. We can determine the optimal weight vector $W^{\star}$ by minimizing the distance between $X_{1}$ and $X_{0} W . X_{1}$ represents the $(k \times 1)$-dimensional feature vector $Z$ of the target city before the Humen Bridge opening. $X_{0}$ is the $(k \times)$ 
matrix containing $k$ characteristic variables of the selected $J$ control groups, and the characteristic vector $Z$ is the main factor affecting regional economic growth or any linear combination of economic growth variables, which is the predictor variable mentioned above. In general, the distance function:

$$
\left\|X_{1}-X_{0} W\right\|=\sqrt{\left(X_{1}-X_{0} W\right)^{\prime} V\left(X_{1}-X_{0} W\right)}
$$

where $V$ is a $(k \times k)$ 's dimensions symmetric positive semidefinite matrices. Although the derivation process here is valid for any $V$, in fact the choice of $V$ will affect the estimated mean square error. Here, the program developed by Abadie et al. is used to calculate $V$, so that the economic growth trajectory of the composite area is the same as that before the opening of the transportation infrastructure. The economic growth trajectory of the treatment group is similar.

\subsection{Variables and Data Description}

\subsubsection{Data Source}

This paper mainly studies the impact of the opening of the Dongguan Humen Bridge on the economic development of Dongguan. The data set used in this research is the panel data of 21 prefecture-level cities in Guangdong Province from 1991 to 2007. In the actual analysis of this article, the data from 2008 and beyond are not used because of the following reasons: 1) The consistency of the statistical rules of data variables. Beginning in 2007, in accordance with the regulations of the National Bureau of Statistics of China, new changes have taken place in the statistical rules of industrial enterprises above designated size. State-owned industrial legal person enterprises whose annual main business income is less than 5 million yuan will no longer be regarded as the industrial statistical scope above the scale. In order to maintain the consistency of statistical indicators, data after 2008 are not included for analysis. 2) Reduce the impact of exogenous shocks. After the 2008 financial crisis, the Chinese government launched ten measures in November 2008 to further expand domestic demand and promote steady and rapid economic growth. Preliminary estimates indicate that the implementation of these ten measures will require an investment of 4 trillion yuan by the end of 2010, including 1.5 trillion yuan invested in major infrastructure construction such as railways, highways, airports, water conservancy, and urban power grid transformation. After that, the transportation infrastructure in various regions has been further improved. The opening of the Guangzhou-Shenzhen high-speed rail in 2011 strengthened the exchange of economic factors in the Pearl River Delta. From 2010 to 2018, China has built a high-density and high-speed rail network in urban agglomerations in the Yangtze River Delta, the Pearl River Delta, and the Bohai Rim. High-speed rail interconnections have been completed among the four major areas in the east, central, west and northeast. In this context, considering that the development of transportation infrastructure after 2008 will weaken the economic effect of Humen Bridge, the data after 2008 is not included for analysis. The original economic data comes from 
the "China Statistical Yearbook", "China City Statistical Yearbook", "Guangdong Statistical Yearbook", "Dongguan Statistical Yearbook" and other related statistical yearbooks. The individual missing values of variables are supplemented by linear interpolation. Dongguan City is the treatment group, and the remaining prefecture-level cities are the control group.

\subsubsection{Variable Description}

Zhang (2012) uses the logarithm of real GDP as the explained variable to measure the impact of transportation infrastructure on economic growth. Liu (2010), Wang and Nie (2010), Liu and Wu (2017), Liu and Wang (2017) were used the logarithm of per capita real GDP as a variable to measure economic growth when studying the impact of policies on economic growth. Yang et al. (2017) used per capita real GDP as the explained variable when studying the impact of the establishment of special economic zones on economic growth. Therefore, referring to previous studies, the explained variable $Y_{i t}$ selected in our article are mainly the logarithm of real GDP (rGDP) and the logarithm of real GDP per capita (rPGDP). In addition, Gao et al. (2012), Liu and Zeng (2018) were used the "Relative Output Value" as an indicator to measure industrial upgrading and transfer in the literature that studied housing price differences and the impact of real estate tax on industrial upgrading and transfer. This article will learn from their practices and use the "Relative Value of GDP" (RVGDP) and the "Relative Value of GDP Per Capita" (RVPGDP) to measure the changes in economic growth. The larger the relative value, the better the development trend of the city's economy. The construction formula of the indicator is as follows:

$$
\begin{aligned}
\operatorname{RVGDP}_{i t} & =\operatorname{GDP}_{i t} /\left(\left(\sum_{j=1}^{n} \mathrm{GDP}_{j t}\right) / n\right) \\
\mathrm{RVPGDP}_{i t} & =\operatorname{PGDP}_{i t} /\left(\left(\sum_{j=1}^{n} \mathrm{PGDP}_{j t}\right) / n\right)
\end{aligned}
$$

According to the idea of SCM, it is necessary to select a series of predictive variables $X_{i t}$ to make the fitting effect and stability effect between the "synthetic treatment group" and the "real treatment group" better. With reference to the research of Liu and $\mathrm{Hu}(2010,2011)$, Zhang (2012) and considering the availability of data, we determined the following predictor variables:

Industrial structure (GDP2): expressed as the proportion of the output value of the secondary industry in each city to the total GDP.

Investment in fixed assets (INV): expressed as the proportion of the total investment in fixed assets of each city in the total GDP.

Government behavior (GOV): expressed as the proportion of government budget expenditure to the total GDP.

Gross Industrial Output Value (GIO): expressed by the gross industrial output value above designated size.

Foreign Direct Investment (FDI): Expressed by the exchange rate of foreign direct investment in each city into RMB.

Total export value (EXPORT): expressed by the export value of each city. 
Road (road): Expressed by the mileage of highways in each city.

Grade road 1 - 4 (road 14): Expressed by traffic mileage of grade 1 - 4 roads in each city.

The data is based on 1990 and adjusted according to the GDP index and per capita GDP index of each city to obtain the actual GDP and per capita actual GDP of each city. Except for RVGDP, RVPGDP and GOV, we took the logarithm of the rest of the variables. Table 1 shows the descriptive statistical results of the variables used in the empirical part.

\section{Empirical Analysis}

\subsection{Empirical Results on the Impact of GDP Growth}

First of all, we verified the impact of the opening of Humen Bridge on the GDP of Dongguan. For the two indexes of lnrGDP and RVGDP of Dongguan before the opening of Humen Bridge, the weight of the city calculated by the synthetic control method is shown in Table 2 and Table 3. Weights reported in Table 2 indicate that rGDP trends in Dongguan are best reproduced by a combination of Zhanjiang, Maoming, Jieyang, Yunfu. With all other cities in the donor pool are assigned zero $\mathrm{W}$-weights. Weights reported in Table 3 indicate that RVGDP trends in Dongguan is best reproduced by a combination of Shaoguan, Maoming, Jieyang, Yunfu, with all other citys in the donor pool are assigned zero $\mathrm{W}$-weights. Notice that, the RMSPE values of lnrGDP and rvGDP in synthetic Dongguan are 0.0226 and 0.0146 respectively, indicating that the growth path of synthetic Dongguan fits the actual growth situation well.

Table 1. Descriptive statistics of major variables.

\begin{tabular}{cccccc}
\hline $\begin{array}{c}\text { Variable } \\
\text { symbol }\end{array}$ & $\begin{array}{c}\text { Number of } \\
\text { observations }\end{array}$ & $\begin{array}{c}\text { Mean } \\
\text { value }\end{array}$ & $\begin{array}{c}\text { Standard } \\
\text { error }\end{array}$ & Min & Max \\
\hline RVGDP & 357 & 1 & 0.891 & 0.190 & 4.102 \\
RVPGDP & 357 & 1 & 0.735 & 0.199 & 2.788 \\
$\ln$ rGDP & 357 & 5.449 & 1.011 & 3.136 & 8.221 \\
$\ln$ rPGDP & 357 & 8.854 & 0.929 & 6.745 & 11.109 \\
$\ln$ GDP2 & 357 & 3.778 & 0.232 & 3.074 & 4.303 \\
$\ln$ GIO & 357 & 5.308 & 1.447 & 1.674 & 8.606 \\
$\ln$ INV & 357 & 3.376 & 0.378 & 2.176 & 4.628 \\
GOV (\%) & 357 & 8.329 & 3.212 & 1.344 & 20.049 \\
$\ln$ EXPORT & 357 & 4.237 & 1.689 & 0.452 & 8.520 \\
$\ln$ FDI & 357 & 2.687 & 1.335 & -1.482 & 5.267 \\
$\ln$ road & 357 & 8.187 & 0.840 & 6.023 & 9.967 \\
$\ln$ road14 & 357 & 8.035 & 0.850 & 5.509 & 9.738 \\
\hline
\end{tabular}

Note. The data are from Statistical Yearbook of China, Statistical Yearbook of Guangdong, Statistical Yearbook of Chinese Cities and Statistical Yearbook of Dongguan from 1991 to 2007, which are compiled by the author. 
Table 2. City Weights of lnrGDP in the Synthetic Dongguan.

\begin{tabular}{cccc}
\hline City & Weight & City & Weight \\
\hline Guangzhou & 0 & Zhongshan & 0 \\
Shenzhen & 0 & Jiangmen & 0 \\
Zhuhai & 0 & Yangjiang & 0 \\
Shantou & 0 & Zhanjiang & 0.058 \\
Foshan & 0 & Maoming & 0.039 \\
Shaoguan & 0 & Zhaoqing & 0 \\
Heyuan & 0 & Qingyuan & 0 \\
Meizhou & 0 & Chaozhou & 0 \\
Huizhou & 0 & Jieyang & 0.458 \\
Shanwei & 0 & Yunfu & 0.445 \\
RMSPE & & 0.0226 & \\
\hline
\end{tabular}

Note. The data is calculated from the compiled panel data through the SCM command.

Table 3. City Weights of RVGDP in the Synthetic Dongguan.

\begin{tabular}{cccc}
\hline City & Weight & City & Weight \\
Guangzhou & 0 & Zhongshan & 0 \\
Shenzhen & 0 & Jiangmen & 0 \\
Zhuhai & 0 & Yangjiang & 0 \\
Shantou & 0 & Zhanjiang & 0.081 \\
Foshan & 0 & Maoming & 0 \\
Shaoguan & 0.015 & Zhaoqing & 0 \\
Heyuan & 0 & Qingyuan & 0 \\
Meizhou & 0 & Chaozhou & 0.486 \\
Huizhou & 0 & Jieyang & Yunfu \\
Shanwei & 0 & 0.0146 & 0.417 \\
RMSPE & & &
\end{tabular}

Note. The data is calculated from the compiled panel data through the SCM command.

Figure 1 and Figure 2 show the development paths of lnrGDP and RVGDP between "Real Dongguan" and "Synthetic Dongguan" from 1991 to 2007, where the vertical dashed line represents the time boundary between the openings of the Humen Bridge. Because the opening of the Humen Bridge was June 1997, the year 1997 was also planned to be the year after the opening of the Humen Bridge, and the year 1991 to 1996 were not affected by the opening of the $\mathrm{Hu}$ men Bridge. 


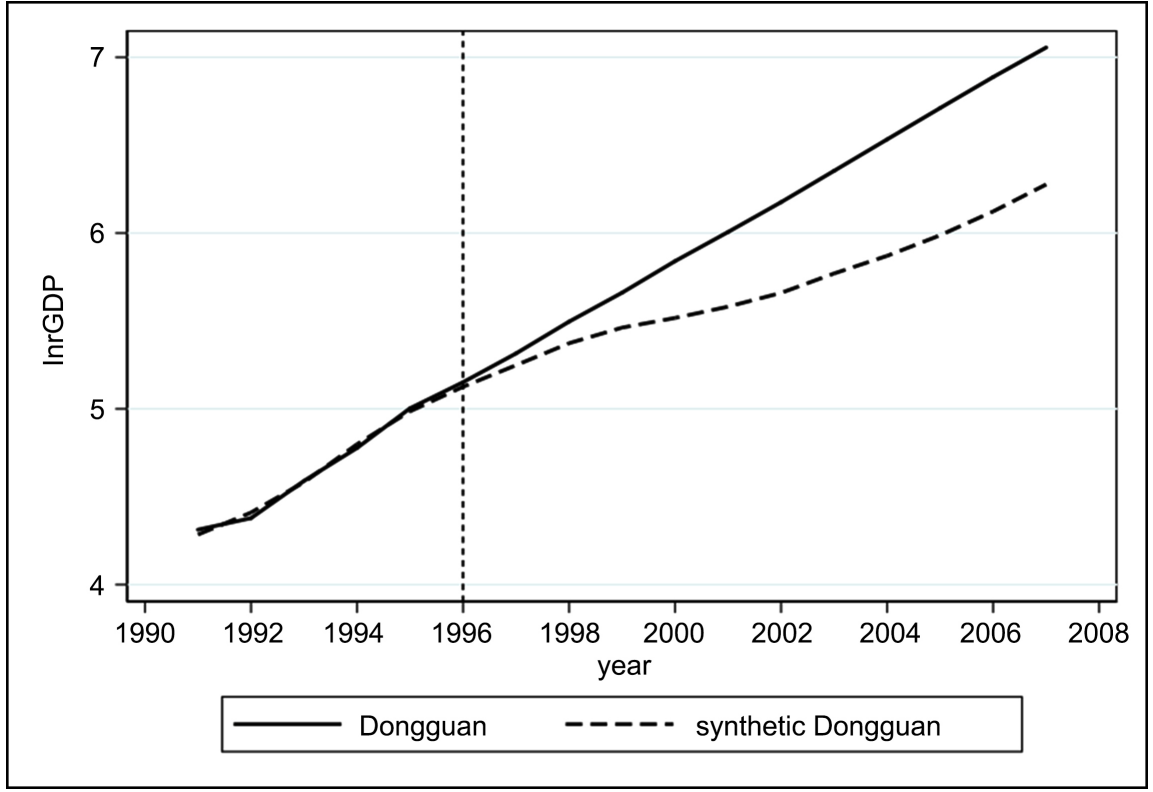

Figure 1. Trends in lnrGDP: Dongguan vs. synthetic Dongguan.

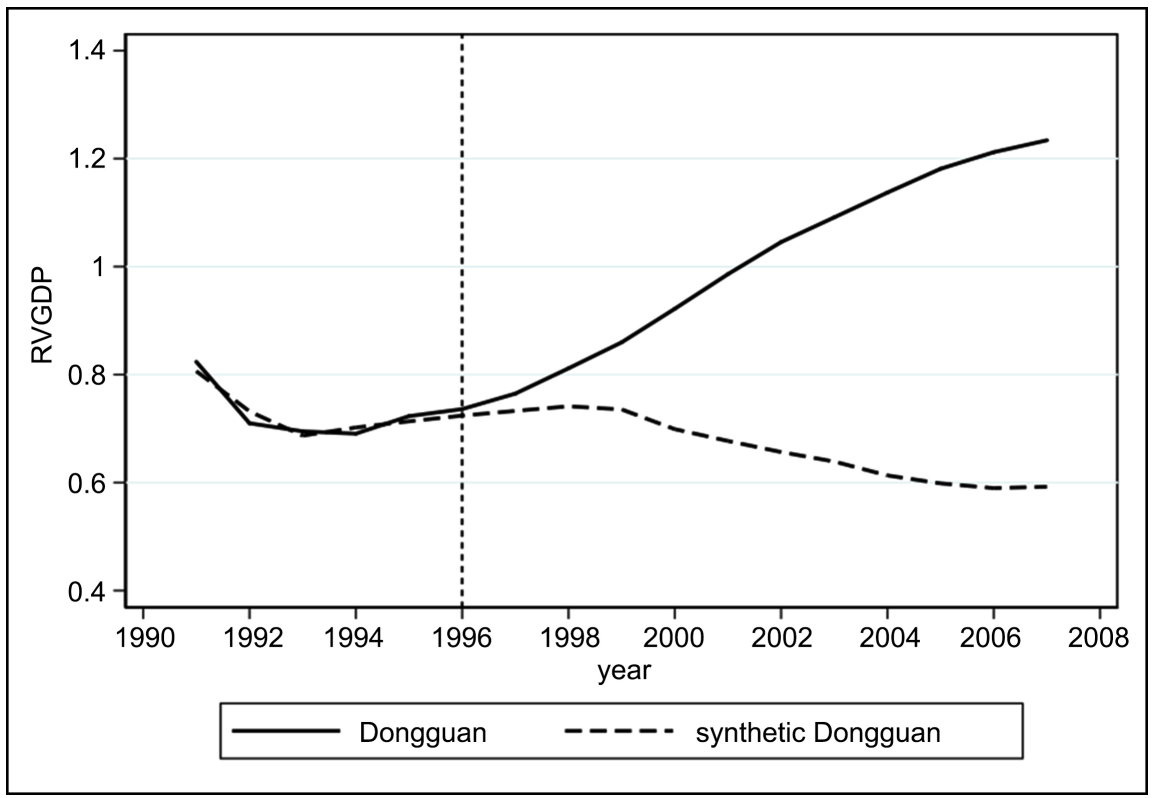

Figure 2. Trends in RVGDP: Dongguan vs. synthetic Dongguan.

Our estimate of the effect of Humen Bridge opening on economic aggregate level in Dongguan is the difference between lnrGDP and RVGDP in Dongguan and in their synthetic version after the opening of Humen Bridge. Figure 1 and Figure 2 show that on the left side of the vertical dotted line, the lnrGDP and RVGDP of Dongguan and its synthetically controlled citie are very close, and the difference is very small, indicating that synthetic Dongguan fits the change path of Dongguan's total GDP well. After the Humen Bridge opened, the two lines began to diverge noticeably, and the development path of its synthetic value is lower than the true value development path. The difference between the solid 
line and the dashed line is exactly the effect of the opening of the Humen Bridge on the total GDP of Dongguan. At the same time, it can be seen from Figure 2 that the development path of RVGDP in synthetic Dongguan shows a steady and slightly downward trend, but the RVGDP of real Dongguan continued to rise after 1996, and the value exceeded 1 around 2002, which showed the development quality and development trend of economy in real Dongguan are better than synthetic Dongguan without Humen Bridge opening.

\subsection{Empirical Results on the Impact of per Capita GDP Growth}

Next, our article verified the impact of the opening of the Humen Bridge on the per capita GDP of Dongguan. Table 4 and Table 5 show the city weights calculated by using the synthetic control method to synthesize the lnrPGDP and RVPGDP in Dongguan. Weights reported in Table 4 and Table 5 indicated that lnrPGDP and RVPGDP's trends in Dongguan is best reproduced by a combination of Shenzhen and Jieyang, with all other citys in the donor pool are assigned zero $\mathrm{W}$-weights. In addition, the synthetic RMSPE values of the lnrPGDP and RVPGDP are 0.0307 and 0.0682 respectively, which also indicated that the growth path of synthetic Dongguan fits the actual growth situation well.

Similar to the discussion above, Figure 3 and Figure 4 show the development path of lnrPGDP and RVPGDP in Dongguan and its synthetic city. On the right side of the vertical dotted line, the development paths of these two predictors gradually deviate, and the development path of the synthetic values is lower than the real Dongguan's values. The difference is exactly the effect of the opening of the Humen Bridge on the real GDP per capita in Dongguan. At the same time, compared to the steady and slight decline in the development path of RVPGDP in synthetic Dongguan, the real value of RVPGDP in Dongguan has continued

Table 4. City Weights of RVPGDP in the Synthetic Dongguan.

\begin{tabular}{cccc}
\hline City & Weight & City & Weight \\
\hline Guangzhou & 0 & Zhongshan & 0 \\
Shenzhen & 0.610 & Jiangmen & 0 \\
Zhuhai & 0 & Yangjiang & 0 \\
Shantou & 0 & Zhanjiang & 0 \\
Foshan & 0 & Maoming & 0 \\
Shaoguan & 0 & Zhaoqing & 0 \\
Heyuan & 0 & Qingyuan & 0 \\
Meizhou & 0 & Chaozhou & 0 \\
Huizhou & 0 & Jieyang & 0.390 \\
Shanwei & 0 & Yunfu & 0 \\
RMSPE & & 0.0307 & \\
\hline
\end{tabular}

Note. The data is calculated from the compiled panel data through the SCM command. 
Table 5. City Weights of rPGDP in the Synthetic Dongguan.

\begin{tabular}{cccc}
\hline City & Weight & City & Weight \\
\hline Guangzhou & 0 & Zhongshan & 0 \\
Shenzhen & 0.776 & Jiangmen & 0 \\
Zhuhai & 0 & Yangjiang & 0 \\
Shantou & 0 & Zhanjiang & 0 \\
Foshan & 0 & Maoming & 0 \\
Shaoguan & 0 & Zhaoqing & 0 \\
Heyuan & 0 & Qingyuan & 0 \\
Meizhou & 0 & Chaozhou & 0 \\
Huizhou & 0 & Jieyang & 0.224 \\
Shanwei & 0 & Yunfu & 0 \\
RMSPE & & 0.0682 & \\
\hline
\end{tabular}

Note. The data is calculated from the compiled panel data through the SCM command.

to rise after 1996, which indicating that the per capita GDP level of Dongguan is getting better. This means that the opening of the Humen Bridge has a significant boost to the per capita GDP of Dongguan, with comparing the assumption that there is no traffic infrastructure opening in Dongguan. To be specific, it can be seen from Figure 3 that the development path gap of lnrPGDP between Dongguan and synthetic Dongguan was around 0.05 before Humen Bridge opened, and the gap fluctuated slightly. But after the Humen Bridge opened, the gap widened, and reached 0.8 by 2007. In the ten years from 1997 to 2007, the lnrPGDP of real Dongguan was about 0.35 higher than the lnrPGDP of the synthetic Dongguan. Figure 4 shows the development quality of Dongguan and synthetic Dongguan in per capita GDP. It can be seen that before the Humen Bridge opened, the RVPGDP of Dongguan and synthetic Dongguan fluctuated between 1.5 and 1.7, with a small development gap. However, after the opening of Humen Bridge, the development path of real Dongguan's RVPGDP has been rising and reached 2.75 in 2007, which is different from the development path of the RVPGDP of synthetic Dongguan under the "counterfactual" state that is stable and slightly declining. The results in Figure 3 and Figure 4 show that the Humen Bridge had promoted the economic growth of Dongguan after its opening, and the quality of development has also been improved.

Further, by observing Figure 1 to Figure 4, we can see that these four indicators are in a steadily rising trend, and the gap with the "counterfactual" synthesis of Dongguan is gradually widening, which indicated that that the opening of Humen Bridge has a sustained growth effect on Dongguan's economic over time. There are also research articles showing that the opening of transportation infrastructure has a lagging period for regional economic benefits (Liu, 2010; Zhou \& Zheng, 2012; Liu \& Wang, 2017). 


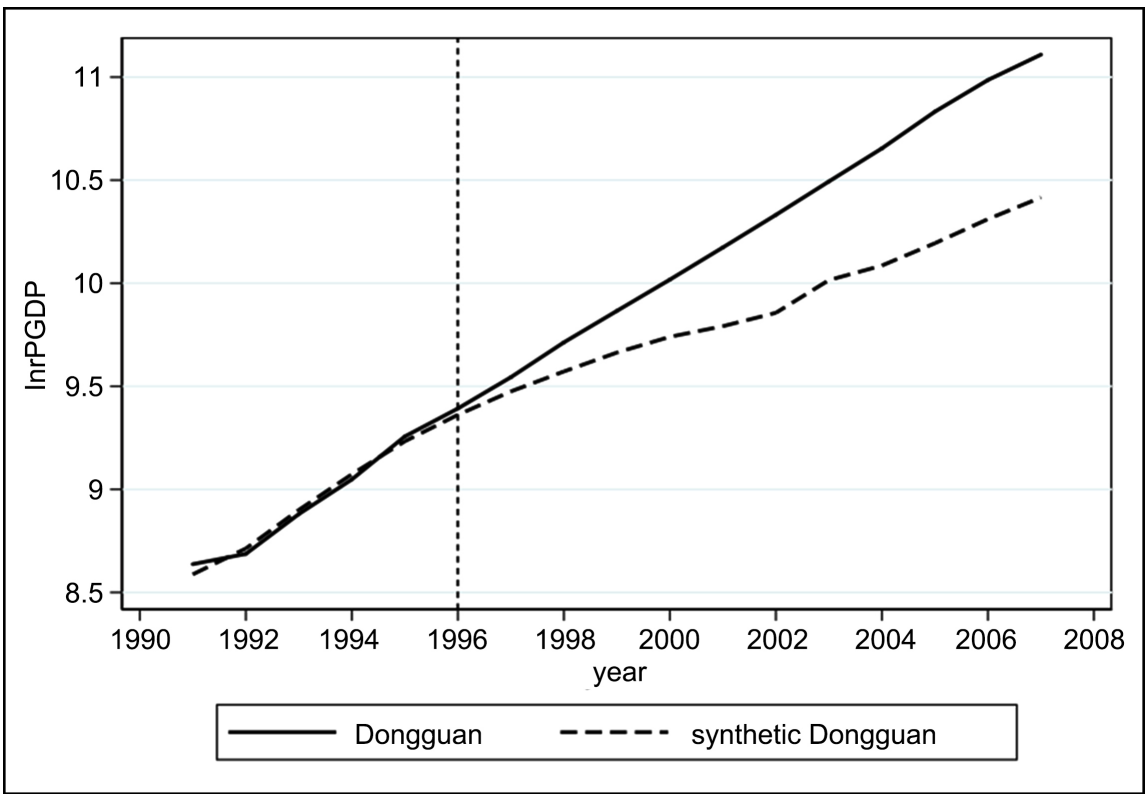

Figure 3. Trends in lnrPGDP: Dongguan vs. synthetic Donggua.

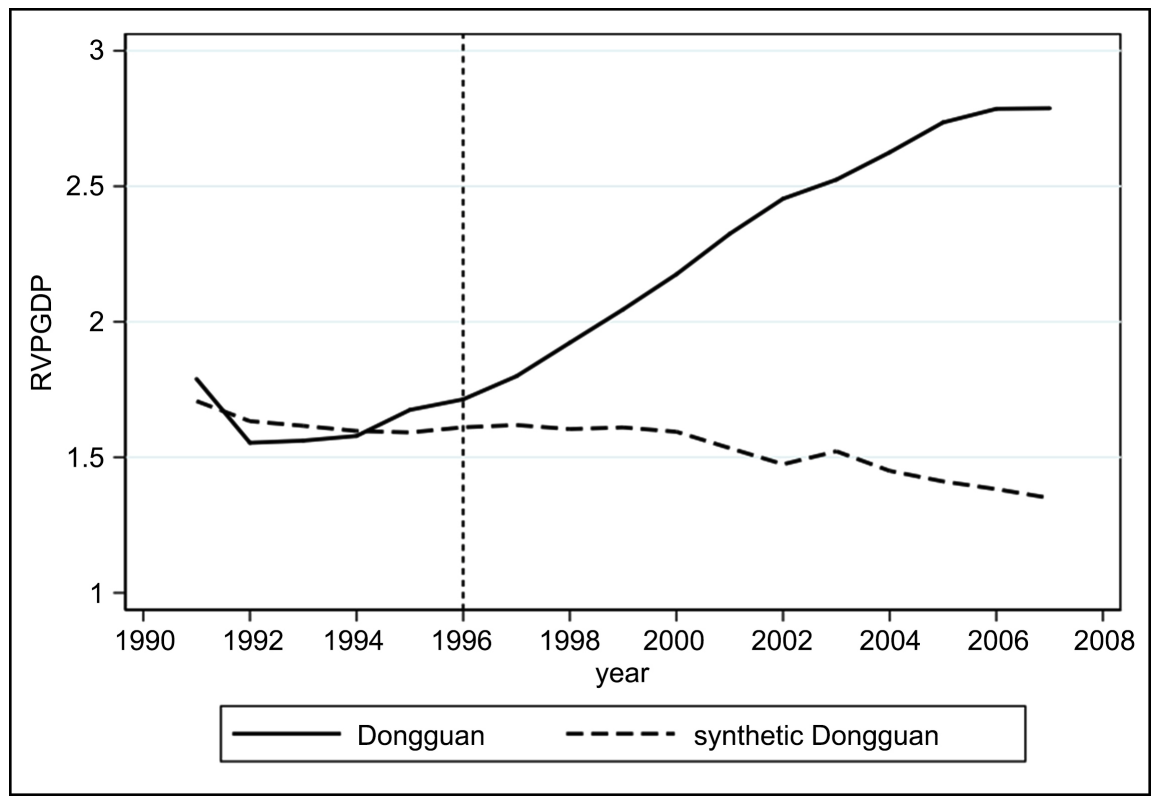

Figure 4. Trends in RVPGDP: Dongguan vs. synthetic Dongguan.

\section{Robustness Test}

\subsection{Permutation Test}

In order to verify the robustness of the previous empirical results, learned from the practices of Abadie and Gardeazabal (2003) and Abadie et al. (2010), we use the Permutation Test to perform robustness testing. The idea of the test is to repeatedly use the synthetic control method to evaluate the impact of the policy implementation (the opening of the Humen Bridge) on the economic development of other control groups and assumed that all the control groups indepen- 
dently have important traffic infrastructures open. We calculate the estimated effect associated with each placebo trial. This iterative process provides us with the estimated gap distribution of the state without intervention, and then compares the actual effect found in the treatment group with the effect produced by the randomly selected control group area. If the difference between the actual effect and the random effect is large enough, the opening of the transportation infrastructure will have a significant effect on the economic growth of the treatment group. The ranking test method can visually show whether there are other areas that are similar to the real treatment group, and the probability of such a situation.

The Permutation Test requires that the synthetic groups and the real treatment group have a good fit before the opening of the transportation infrastructure. Therefore, in this placebo test method, if the calculated RMSPE value during the iterative process is too large, it means the sample's fitting effect of the time period before the opening of the transportation infrastructure is not good enough, so even if the difference of the explained variable of the sample is large in the later period, it cannot convincingly reflect the effect of the event. Therefore, if a sample has an unsatisfactory fitting effect between the synthetic object and itself before the event happened, we will no longer analyze the permutation test of this city. We excluded cities that had a RMSPE of more than 2 times the RMSPE of Dongguan. Figures 5-8 display the results for the placebo test, the black line represents Dongguan, and the dotted lines represent the cities of the control group.

Taking predictive variables lnrGDP and rvGDP as examples, it can be seen that before 1996, there was not much difference between Dongguan and the cities in the control group. However, after 1996, the gap between Dongguan and the control cities began to widen, and Dongguan's development path was located outside compare with other cities. The greater the difference value, the stronger the promotion effect brought by the opening of Humen Bridge. That indicated the opening of Humen Bridge had changed the GDP growth trend of Dongguan and brought positive effects. Because these two figures included 17 control cities, the probability of estimating a gap of the magnitude of the gap for Dongguan under a random permutation of the intervention in our data is $5.6 \%$, a test level typically used in conventional tests of statistical significance. Similarly, it can also be proved that the growth trend of per capita GDP in Dongguan also showed positive and significant effects after 1996, the results are shown in Figure 7 and Figure 8. The results of the placebo test are basically consistent with the results of the empirical analysis in part IV ${ }^{1}$.

\footnotetext{
${ }^{1}$ When analyzing the predictive variables of lnrGDP, the four cities of Guangzhou, Heyua, Jieyang and Yunfu with poor fitting degree were removed, leaving 17 sample cities. When analyzing the predictive variables of RVGDP, the four cities of Guangzhou, Shenzhen, Foshan and Yunfu with poor fitting degree were removed, leaving 17 sample cities. When analyzing the predictive variables of lnrPGDP, the four cities of Shenzhen, Zhuhai, Heyuan and Jieyang with poor fitting degree were removed, leaving 17 sample cities. When analyzing the predictive variables of RVPGDP, the two cities of Shenzhen and Zhuhai with poor fitting degree were removed, leaving 19 sample cities.
} 


\subsection{DID for Further Testing}

Some researchers were all used the DID method as robustness test when studied the impact of policy effects on the economy (Liu \& Fan, 2013; Liu \& Wu, 2017; Liu \& Zeng, 2018). Therefore, based on their approach, in order to ensure the robustness of the analysis, we used the DID with fixed effects to test the robustness of the predictor variables. The econometric model is set as follows:

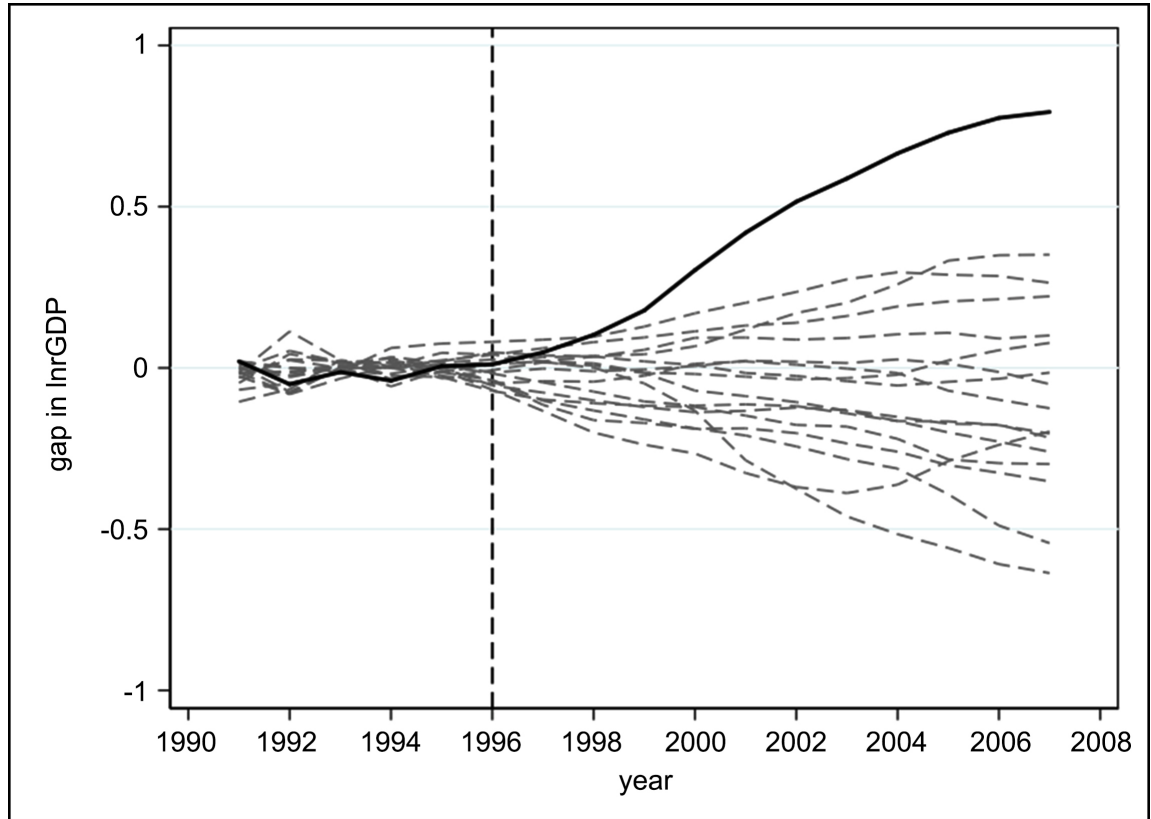

Figure 5. lnrGDP Gaps in Dongguan and Placebo Gaps in 17 Control cities (Discards cities with RMSPE Two Times Higher than Dongguan's).

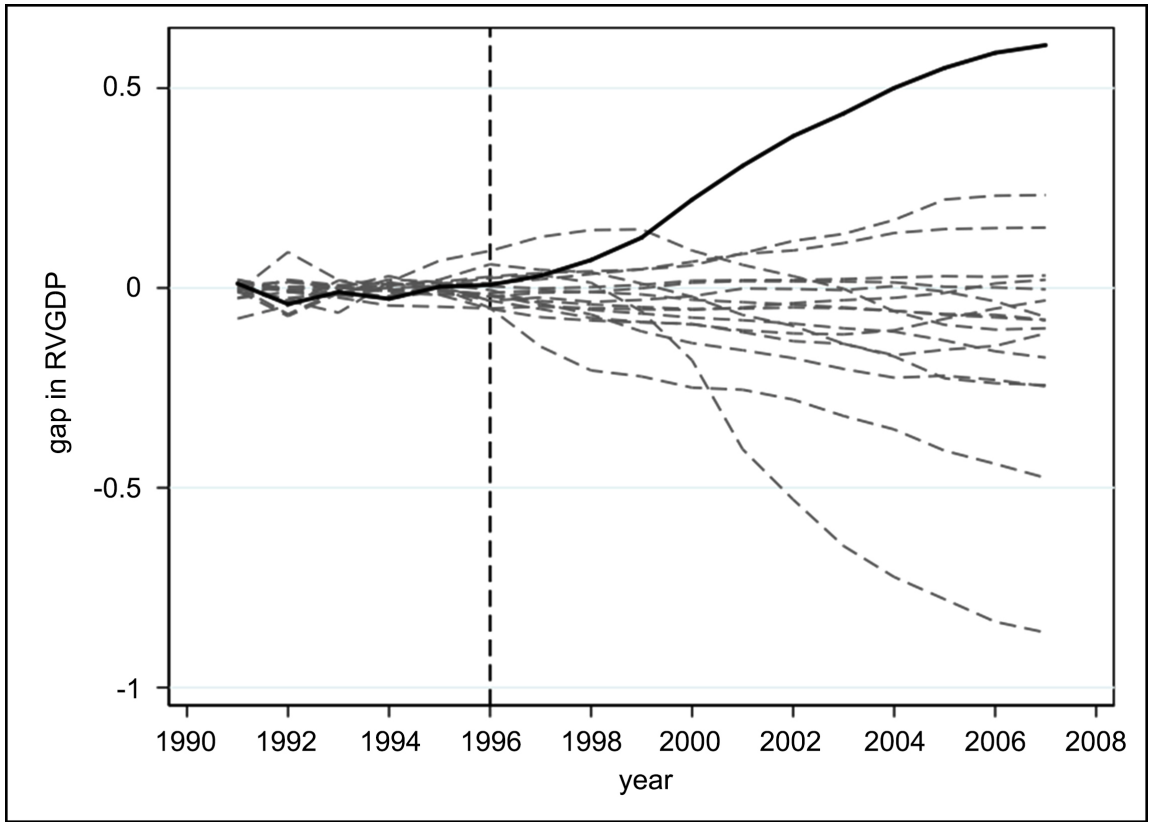

Figure 6. RVGDP Gaps in Dongguan and Placebo Gaps in 17 Control cities (Discards cities with RMSPE Two Times Higher than Dongguan's). 


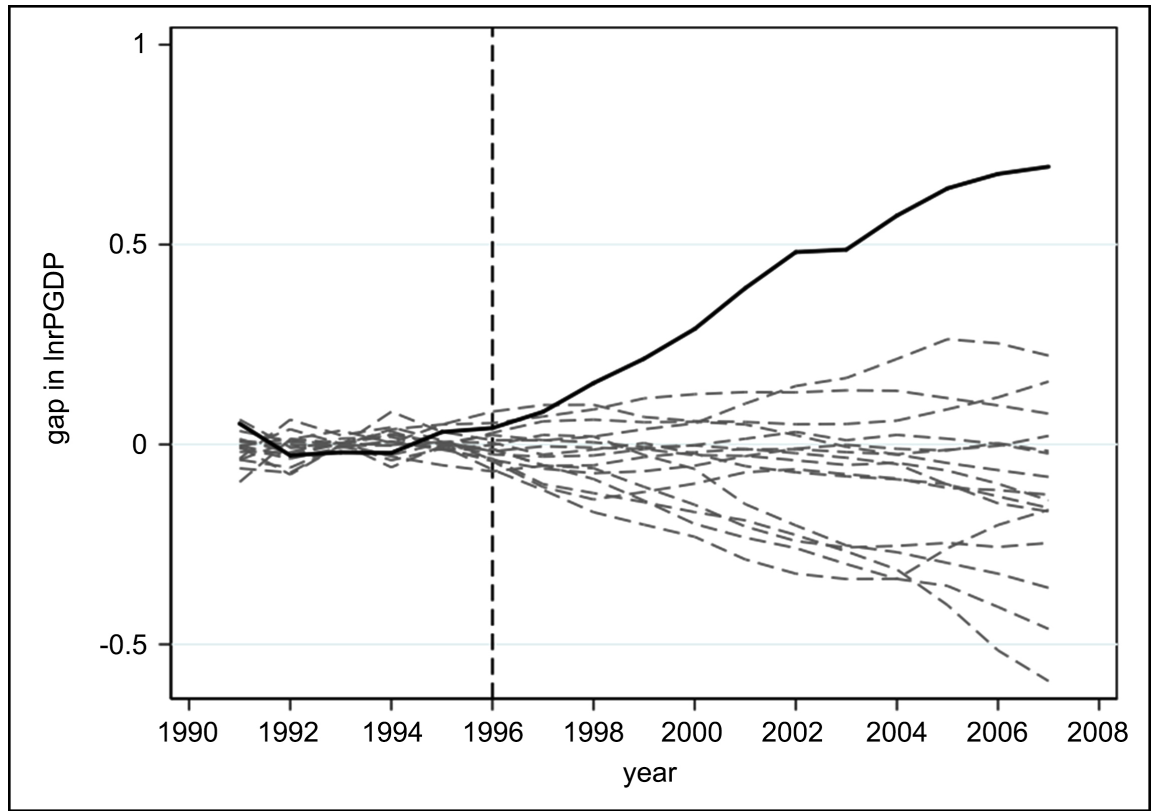

Figure 7. lnrPGDP Gaps in Dongguan and Placebo Gaps in 17 Control cities (Discards cities with RMSPE Two Times Higher than Dongguan's).

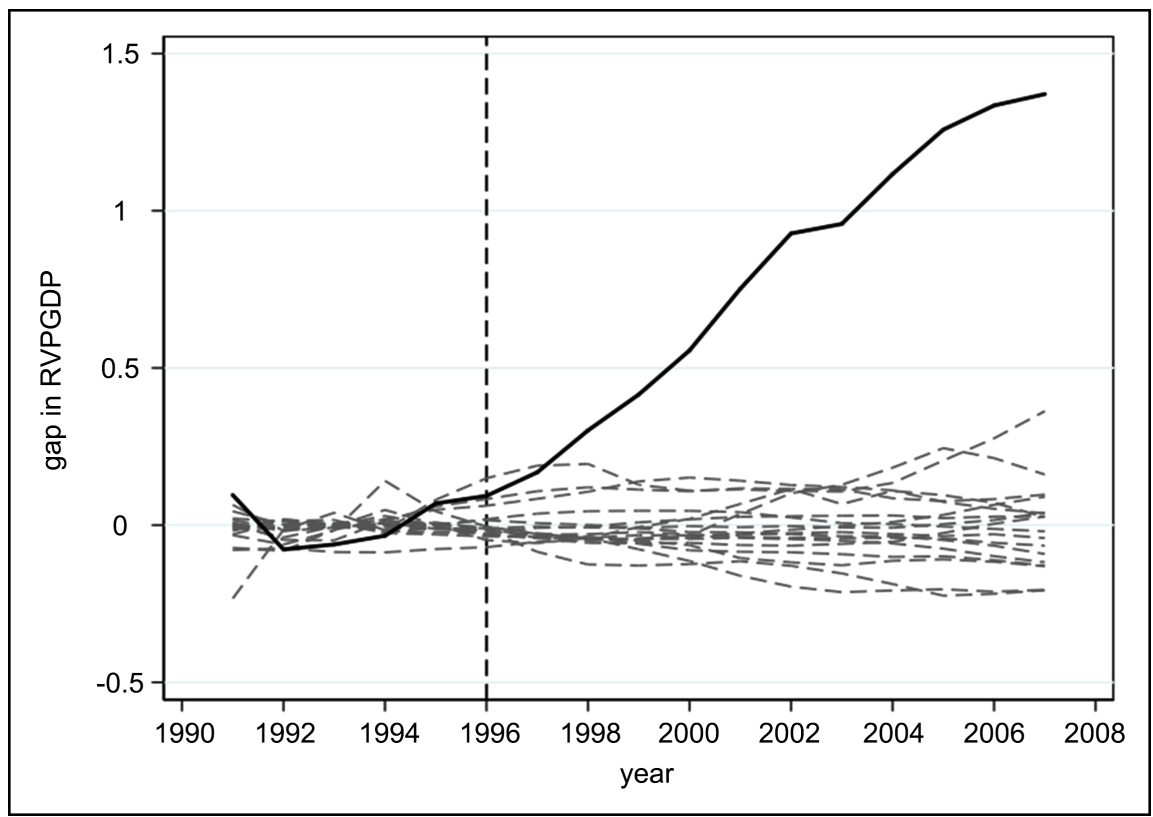

Figure 8. RVPGDP Gaps in Dongguan and Placebo Gaps in 19 Control cities (Discards cities with RMSPE Two Times Higher than Dongguan's).

$$
\begin{gathered}
Y_{i t}=\alpha_{0}+\alpha_{1} D_{t}+\alpha_{2} G_{i}+\beta D_{t} * G_{i}+\delta_{i}+\gamma_{t}+\varepsilon_{i t} \\
Y_{i t}=\alpha_{0}+\alpha_{1} D_{t}+\alpha_{2} G_{i}+\beta D_{t} * G_{i}+\theta X_{i t}+\delta_{i}+\gamma_{t}+\varepsilon_{i t}
\end{gathered}
$$

Equation (8) is the general form without adding control variables. Equation (9) is the form of adding control variables. Where $Y_{i t}$ denote economic growth variable for city $i$ at year $t . G_{i}$ is a dummy variable (treatment group =1, control group $=0) . \quad D_{t}$ is a dummy variable of time (after the opening of the bridge 
$=1$, before the opening of the bridge $=0$ ). The interaction term represents the effect of the treatment group after the bridge was opened, and the coefficient $\beta$ is the treatment effect that the model focuses on. In addition, $X_{i t}$ is the set of control variables, $\delta_{i}$ is the regional fixed effect, $\gamma_{t}$ is the annual fixed effect, and $\varepsilon_{i t}$ is the random error term.

Table 6 reports the estimated results of the Humen Bridge opening on Dongguan's lnrGDP and RVGDP. Columns 1 and 3 use Equation (8) as the basic model, and the interaction term coefficients are all significantly positive without controlling other influencing factors. Columns 2 and 4 use formula 9 as the basic model. The interaction term with $\ln$ GDP as the economic growth indicator is significantly positive when other influencing factors are controlled. However, the interaction term with RVGDP as the economic growth indicator is positive when other influencing factors are controlled, but it is no longer significant. The possible reason is that in all the prefecture-level city samples in Guangdong Province included special first-tier cities (Guangzhou, Shenzhen), their economic development level is significantly higher than second-tier and below cities, which may cause estimation results are not significant ${ }^{2}$. But generally speaking, the results of the robustness estimation are consistent with the empirical results and permutation test.

Table 7 reports the estimated results at the level of Per capita GDP in Dongguan. The interaction coefficient in columns 1 and 4 show that the estimated results are positive and significant at the $1 \%$ level, which indicated that the opening of Humen Bridge has a positive and significant effect on the per capita GDP level. The opening of Humen Bridge has promoted the growth trend of per capita GDP in Dongguan, made its growth faster. This estimation result is basically consistent with the previous empirical results and permutation test.

Furthermore, this article replaces the indicators to measure regional economic growth with GDP growth rate $\left(g_{1}\right)$ and per capita GDP growth rate $\left(g_{2}\right)$. Columns 5 and 6 in Table 6 and Table 7 report the estimation results. The coefficient of the interaction term reflects the impact of the completion of Humen Bridge on the GDP growth rate and per capita GDP growth rate of Dongguan. The interaction term's coefficients obtained are all significantly positive, indicating that the opening of Humen Bridge has a positive and significant impact on the GDP growth rate and per capita GDP growth rate of Dongguan city.

\section{Conclusions and Policy Recommendations}

Most of the existing literature proved that transportation infrastructure had significant effects in promoting economic growth, but most of the studies are based

\footnotetext{
${ }^{2}$ A similar situation had occurred when Liu Naiquan and Wu You (2017) used PSM-DID for robustness analysis. Therefore, in further analysis, we eliminated Guangzhou and Shenzhen, two first-tier cities with excellent economic development, to avoid the impact of special cities. Then we still use the DID with fixed effect to estimate, and the result is that the interaction term is 0.18 and is significant at the $1 \%$ significance level. Therefore, the test results estimated by the DID method verify the robustness of the above research conclusions.
} 
Table 6. The impact of the opening of Humen Bridge on Dongguan's lnrGDP, RVGDP and GDP growth rate.

\begin{tabular}{ccccccc}
\hline & $(1)$ & $(2) \mathrm{FE}$ & $(3)$ & $(4) \mathrm{FE}$ & $(5)$ & $(6) \mathrm{FE}$ \\
\hline Explained variable & lnrGDP & lnrGDP & RVGDP & RVGDP & $g_{1}$ & $g_{1}$ \\
& $0.41^{\star}$ & $0.12^{\star * *}$ & $0.31^{\star * *}$ & 0.03 & $8.43^{* * *}$ & $12.95^{* * *}$ \\
Interaction term $\beta$ & $(0.23)$ & $(0.04)$ & $(0.11)$ & $(0.05)$ & $(2.69)$ & $(2.64)$ \\
$X_{i t}$ & - & Yes & - & Yes & - & Yes \\
$\delta_{i}$ & - & Yes & - & Yes & - & Yes \\
$\gamma_{t}$ & - & Yes & - & Yes & - & Yes \\
$N$ & 357 & 357 & 357 & 357 & 357 & 357 \\
$R^{2}$ & 0.270 & 0.987 & 0.002 & 0.575 & 0.244 & 0.587 \\
\hline
\end{tabular}

Notes: 1$)^{*},{ }^{* *}$ and ${ }^{* * *}$ denote significant at $10 \%, 5 \%$ and $1 \%$ level, respectively. 2) FE means DID with fixed effects.

Table 7. The impact of the opening of Humen Bridge on Dongguan's lnrPGDP, RVPGDP and per capita GDP growth rate.

\begin{tabular}{ccccccc}
\hline & $(1)$ & $(2) \mathrm{FE}$ & $(3)$ & $(4) \mathrm{FE}$ & $(5)$ & $(6) \mathrm{FE}$ \\
\hline Explained variable & lnrPGDP & lnrPGDP & RVPGDP & RVPGDP & $g_{2}$ & $g_{2}$ \\
Interaction term $\beta$ & $0.44^{\star *}$ & $0.26^{\star * *}$ & $0.77^{\star * *}$ & $0.69^{\star * *}$ & $7.67^{\star * *}$ & $10.32^{\star * \star}$ \\
$X_{i t}$ & $(0.21)$ & $(0.05)$ & $(0.13)$ & $(0.07)$ & $(2.60)$ & $(2.49)$ \\
$\delta_{i}$ & - & Yes & - & Yes & - & Yes \\
$\gamma_{t}$ & - & Yes & - & Yes & - & Yes \\
$N$ & - & Yes & - & Yes & - & Yes \\
$R^{2}$ & 357 & 357 & 357 & 357 & 357 & 357 \\
\hline
\end{tabular}

Notes: 1$)^{\star}, * *$ and ${ }^{* * *}$ denote significant at $10 \%, 5 \%$ and $1 \%$ level, respectively. 2) FE means DID with fixed effects.

on the stock or investment of transportation infrastructure as an explanatory variable. This article innovatively examines the economic growth effects of the opening of key infrastructures, takes the completion of the Dongguan Humen Bridge as a natural experiment, uses the synthetic control method of policy evaluation, and verifies it based on panel data from 21 prefecture-level cities in Guangdong Province from 1991 to 2007. The empirical research results show that the opening of the Humen Bridge has a significant role in promoting the economic growth of Dongguan. The specific performance is as follows: Compared with the synthetic Dongguan under the "counterfactual" state, the opening of the Humen Bridge had changed the growth of Dongguan's real GDP and per capita GDP's growth trend. During the study period, the opening of the bridge has continued to enhance economic growth. In response to the above research conclusions, two robustness test methods are designed: Permutation Test and 
DID with fixed effects method. The conclusions obtained by using these two methods are basically consistent with the empirical conclusions, which shows that the research results are robust.

The empirical results show that the opening of transportation infrastructure in important geographical locations has a significant role in promoting local economic development. The corresponding policy implications are:

From the perspective of public investment, we must focus on the construction of transportation infrastructure in important geographical locations. As the main component of public goods, transportation infrastructure has externalities that allow it to be directly invested in the process of social production after it is completed, reducing the circulation time of production factors and transportation costs, and expanding regional accessibility and communication. China has a vast territory, uneven distribution of endowments between regions, and unbalanced development. The problem of unbalanced development has always existed. It is necessary to give full play to the role of important geographical locations, improve transportation facilities in relatively backward and poor areas, build a good transportation network, and improve the communication efficiency of economic factors, then promote the economic development of the region.

From the perspective of overall regional development, it is necessary to coordinate relatively balanced development between regions. Imperfect transportation infrastructure may have a negative effect on the economic development of underdeveloped areas. Because as the flow cost decreases, the production factors of underdeveloped areas will flow to relatively developed areas, which makes the economic agglomeration effect of developed areas more obvious. Therefore, it is necessary to prevent the oversaturation of the central area caused by the "siphon effect" ${ }^{3}$ of the transportation infrastructure, and to prevent the excessive loss of economic factors in the surrounding areas. Reasonably coordinate the layout of the transportation network and use the external functions of the transportation infrastructure to help upgrade the "central-peripheral" industry.

Although we have argued in the preceding article that the opening of Humen Bridge has a positive impact on the economic growth of Dongguan. It is worth noting that there are still some deficiencies worth discussing in this paper. One caveat of the article is that the control cities we found were only prefecture-level cities in Guangdong province. Due to the huge development gap between PRD (the Pearl River delta) and non-PRD, these control cities were not good enough to give weights to the synthetic city. Selecting the control cities with similar economic development status to the experimental group, and estimating the

\footnotetext{
${ }^{3}$ Siphon Effect: originally refers to the physical phenomenon that liquid will flow from one side with high pressure to the other side with low pressure due to the existence of gravity and potential energy difference between liquid molecules. The "siphon effect" in economics refers to the fact that with the continuous development of a central city, when it grows into a large city or even a first-tier super-large city, it will attract talents, investment, population, information and other high-quality resources from disadvantaged areas due to the high concentration of high-quality medical care, education, infrastructure resources and abundant capital. For big cities, this will lead to further improvement of competitiveness and further expansion of scale.
} 
impact of the opening of transportation infrastructure on economic growth more accurate remains a very important next step in this research agenda.

\section{Conflicts of Interest}

The author declares no conflicts of interest regarding the publication of this paper.

\section{References}

Abadie, A., \& Gardeazabal, J. (2003). The Economic Costs of Conflict: A Case Study of the Basque Country. American Economic Review, 93, 113-132. https://doi.org/10.1257/000282803321455188

Abadie, A., Diamond, A., \& Hainmueller, J. (2010). Synthetic Control Methods for Comparative Case Studies: Estimating the Effect of California's Tobacco Control Program. Journal of the American Statistical Association, 105, 493-505. https://doi.org/10.1198/jasa.2009.ap08746

Ando, M. (2015). Dreams of Urbanization: Quantitative Case Studies on the Local Impacts of Nuclear Power Facilities Using the Synthetic Control Method. Journal of Urban Economics, 85, 68-85. https://doi.org/10.1016/j.jue.2014.10.005

Aschauer, D. A. (1989). Is Public Expenditure Productive. Journal of Monetary Economics, 23, 177-200. https://doi.org/10.1016/0304-3932(89)90047-0

Atack, J., Bateman, F., Haines, M., \& Margo, R. A. (2010). Did Railroads Induce or Follow Economic Growth? Urbanization and Population Growth in the American Midwest, 1850-1860. Social Science History, 34, 171-197. https://doi.org/10.1215/01455532-2009-024

Banerjee, A., Duflo, E., \& Qian, N. (2012). On the Road: Access to Transportation Infrastructure and Economic Growth in China. NBER Working Paper, No. 17897. https://doi.org/10.3386/w17897

Barro, R. (1990). Government Spending in a Simple Model of Endogeneous Growth. Journal of Political Economy, 98, 103-S125. https://doi.org/10.1086/261726

Bougheas, S., Demetriades, P. O., \& Morgenroth, E. L. W. (1999). Infrastructure, Transport Costs and Trade. Journal of International Economics, 47, 169-189. https://doi.org/10.1016/S0022-1996(98)00008-7

Button, K., \& Taylor, S. (2000). International Air Transportation and Economic Development. Journal of Air Transport Management, 6, 209-222. https://doi.org/10.1016/S0969-6997(00)00015-6

Chandra, A., \& Thompson, E. (2000). Does Public Infrastructure Affect Economic Activity? Evidence from the Rural Interstate Highway System. Regional Science and Urban Economics, 30, 457-490. https://doi.org/10.1016/S0166-0462(00)00040-5

Clark, X., Dollar, D., \& Micco, A. (2004). Port Efficiency, Maritime Transport Costs, and Bilateral Trade. Journal of Development Economics, 75, 417-450. https://doi.org/10.1016/j.jdeveco.2004.06.005

Demurger, S. (2001). Infrastructure Development and Economic Growth: An Explanation for Regional Disparities in China. Journal of Comparative Economics, 29, 95-117. https://doi.org/10.1006/jcec.2000.1693

Evans, P., \& Karras, G. (1994a). Are Government Activities Productive? Evidence from a Panel of U.S. States. The Review of Economics and Statistics, 76, 1-11. https://doi.org/10.2307/2109821 
Evans, P., \& Karras, G. (1994b). Is Government Capital Productive? Evidence from a Panel of Seven Countries. Journal of Macroeconomics, 16, 271-279. https://doi.org/10.1016/0164-0704(94)90071-X

Fedderke, J. W., \& Bogetic, Z. (2009). Infrastructure and Growth in South Africa: Direct and Indirect Productivity Impacts of 19 Infrastructure Measures. World Development, 37, 1522-1539. https://doi.org/10.1016/j.worlddev.2009.01.008

Fernald, J. G. (1999). Roads to Prosperity? Assessing the Link between Public Capital and Productivity. American Economic Review, 89, 619-638. https://doi.org/10.1257/aer.89.3.619

Francois, J., \& Manchin, M. (2013). Institutions, Infrastructure and Trade. World Development, 46, 165-175. https://doi.org/10.1016/j.worlddev.2013.02.009

Fujimura, M., \& Edmonds, C. (2006). Impact of Cross-Border Transport Infrastructure on Trade and Investment in the Gms. Adb Institute Discussion Paper, No. 48.

Gao, B., Chen, J., \& Zou, L. H. (2012). Housing Price’ Regional Differences, Labor Mobility and Industrial Upgrading. Economic Research Journal, 1, 66-79.

Garcia-Mila, T., \& Mcguire, T. J. (1992). The Contribution of Publicly Provided Inputs to States Economies. Regional Science and Urban Economics, 22, 229-241. https://doi.org/10.1016/0166-0462(92)90013-Q

Guo, G. Z., Liu, R. G., \& Huang, Z. Y. (2019). Cars on the Road: An Economic Growth Model of Road Infrastructure's Effect on Consumption and Economic Growth. Economic Research Journal, 3, 166-180.

Holtz-Eakin, D., \& Schwartz, A. E. (1995). Spatial Productivity Spillovers from Public Infrastructure: Evidence from State Highways. International Tax and Public Finance, 2, 459-468. https://doi.org/10.1007/BF00872777

Huang, J. L., \& Li, K. W. (2006). Export Openness, Regional Market Size and Economic Growth. Economic Research Journal, 6, 27-38.

Institute of Industrial Economics of CASS (2002). The Relationship between Infrastructure Investment and Manufacturing Industry Growth. Economic Research Journal, 2, 37-47.

Krugman, P. (1991). Increasing Return and Economic Geography. Journal of Political Economy, 99, 483-499. https://doi.org/10.1086/261763

Li, H., \& Li, Z. G. (2009). Impact of Transportation Infrastructure Investment on Enterprise Inventory-An Empirical Study Based on Panel Data of Chinese Manufacturing Enterprises. Management World, 8, 73-80.

Limao, N., \& Venables, A. J. (2001). Infrastructure, Geographical Disadvantage, Transport Costs and Trade. The World Bank Economic Review, 15, 451-479.

https://doi.org/10.1093/wber/15.3.451

Liu, B. L., Wu, P., \& Liu, Y. H. (2010). Transportation Infrastructure and the Increase in TFP in China-Spatial Econometric Analysis on Provincial Panel Data. China Industrial Economics, 3, 54-64.

Liu, J. Y., \& Fan, Z. Y. (2013). Effect Evaluation of China's Property Tax Pilot: A Study Based on Synthetic Control Method. The Journal of World Economy, 11, 117-135.

Liu, N. Q., \& Wu, Y. (2017). Can the Enlargement in Yangtze River Delta Boost Regional Economic Common Growth. China Industrial Economics, 6, 79-97.

Liu, S. L., \& Hu, A. G. (2010). Transport Infrastructure and Economic Growth: Perspective from China's Regional Disparities. China Industrial Economics, 4, 14-23.

Liu, S. L., \& Hu, A. G. (2011). Transportation Infrastructure and Regional Economic In- 
tegration in China. Economic Research Journal, 3, 72-82.

Liu, Y. (2010). Transport Infrastructure Investment, Regional Economic Growth and the Spatial Spillover Effects-Based on Highway and Marine's Panel Data Analysis. China Industrial Economics, 12, 37-46.

Liu, Y. J., \& Zeng, X. M. (2018). Research on the Influence of Industrial Transfer from the Property Taxes: Empirical Research from Chongqing and Shanghai. China Industrial Economics, 11, 98-116.

Liu, Z. H., \& Wang, L. H. (2017). Research on Regional Economic Effect and Influence Mechanism of Transportation Infrastructure-Evidence from Zheng-Xi High-Speed Railway. Economic Science, 2, 32-46.

Nordas, H. K., \& Piermartini, R. (2004). Infrastructure and Trade. Wto Staff Working Paper, No. Ersd-2004-04.

Pradhan, R. P., \& Bagchi, T. P. (2013). Effect of Transportation Infrastructure on Economic Growth in India: the VECM Approach. Research in Transportation Economics, 38, 139-148. https://doi.org/10.1016/j.retrec.2012.05.008

Ren, X. H., \& Zhang, Z. Y. (2010). Spatial Econometric Analysis of Location Selection of Transportation Infrastructure and Manufacturing industry. Inquiry into Economic Issues, 10, 13-17.

Roberts, M., Deichmann, U., Fingleton, B., \& Shi, T. (2012). Evaluating China's Road to Prosperity: A New Economic Geography Approach. Regional Science and Urban Economics, 42, 580-594. https://doi.org/10.1016/j.regsciurbeco.2012.01.003

Sheng, D., Bao, Q., \& Wang, Y. J. (2011). Influence of Infrastructure on the Export Behavior of Chinese Enterprises: "Intensive Margin" or "Extended Margin”. The Journal of World Economy, 1, 17-36.

Shi, Z. K., Shao, J., \& Pu, Z. N. (2018). Effects of Quality Improvements in Transportation Infrastructure on Total Factor Productivity Growth: Evidence of Chinese Railway Speed Acceleration. The Journal of World Economy, 6, 127-151.

Tatom, J. A. (1991). Public Capital and Private Sector Performance. Federal Reserve Bank of St. Louis Review, 73, 3-15. https://doi.org/10.20955/r.73.3-15

Venables, A. J. (1996). Equilibrium Locations of Vertically Linked Industries. International Economic Review, 37, 341-359. https://doi.org/10.2307/2527327

Wang, R. F., \& Wang, J. J. (2007). Infrastructure and China's Economic Growth: Research Based on VAR Method. The Journal of World Economy, 3, 13-21.

Wang, X. B., \& Nie, H. F. (2010). Administrative Division Adjustment and Economic Growth. Management World, 4, 42-53.

Yang, J. G., Zhou, L. L., \& Zou, H. F. (2017). Evaluation of Economic Growth Effect Established in China's Special Economic Zones-Based on Analysis of Synthetic Control Method. Economic Perspectives, 1, 41-51.

Zhang, H. R., \& Yi, B. Z. (2012). Infrastructure, Space Overflow and Regional Total Factor Productivity-An Empirical Study Based on the Durbin Model of Spatial Panel in 266 Cities in China. Economist, 2, 61-67.

Zhang, X. L. (2007). Regional Comparative Analysis on the Relationship between Transport Infrastructure and Economic Growth in China. Journal of Finance and Economics, $8,51-63$.

Zhang, X. L. (2012). Has Transport Infrastructure Promoted Regional Economic Growth-With an Analysis of the Spatial Spillover Effects of Transport Infrastructure. Social Sciences in China, 3, 60-77. 
Zhang, X., Wang, X., Wan, G. H., \& Sun, F. C. (2018). A Unified Framework of Road Infrastructure's Growth Effect. Economic Research Journal, 1, 50-64.

Zhou, H., \& Zheng, X. T. (2012). Quality of Transportation Infrastructure and Economic Growth: Evidence from China's Railway Speeding Up. The Journal of World Economy, 1, 78-97. 